\title{
Liver eosinophilic infiltrate is a significant finding in patients with chronic hepatitis $\mathrm{C}$
}

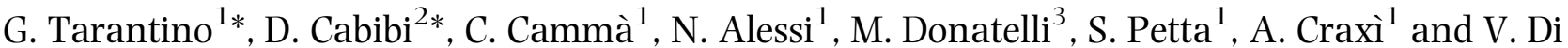 \\ Marco $^{1}{ }^{1}$ Cattedra ed Unità Operativa di Gastroenterologia ed Epatologia, Dipartimento Biomedico di Medicina Interna e Specialistica, University of \\ Palermo; ${ }^{2}$ Dipartimento di Patologia Umana, University of Palermo; and ${ }^{3}$ Dipartimento Biomedico di Medicina Interna e Specialistica, University of \\ Palermo, Palermo, Italy
}

Received August 2007; accepted for publication November 2007

SUMMARY. Eosinophilic infiltrate of liver tissue is described in primary cholestatic diseases, hepatic allograft rejection and drug-induced liver injury, but its significance and its implications in chronic hepatitis $\mathrm{C}$ are unknown. The aim of this study was to investigate the clinical significance of eosinophilic liver infiltrate in patients with chronic hepatitis C. We retrospectively evaluated 147 patients with chronic hepatitis C. The presence of eosinophilic infiltrate was investigated in liver biopsies, and a numeric count of eosinophilic leucocytes in every portal tract was assessed. An eosinophilic infiltrate of liver tissue ( $\geq 3$ cells evaluated in the portal/periportal spaces) was observed in 46 patients (31\%), and patients who consumed drugs had an odds ratio (OR) of 4.02 (95\% CI: 1.62-9.96) to have an eosinophilic infiltrate in liver biopsy. By logistic regression analysis, the presence of steatosis was independently associated with eosinophilic infiltrate (OR
5.86; 95\% CI: 2.46-13.96) and homeostasis model assessment-score (OR 1.18; 95\% CI: 1.00-1.39). Logistic regression analysis also showed that fibrosis staging $\geq 2$ by Scheuer score was associated with grading $>1$ by Scheuer score (OR 6.82; 95\% CI 2.46-18.80) and eosinophilic infiltrate (OR 4.00; 95\% CI 1.23-12.91). In conclusion, we observed that the eosinophilic infiltrate of liver tissue was significantly more frequent in patients who assumed drugs, and found a significant association between eosinophilic infiltrate, liver steatosis and liver fibrosis. These preliminary data could lead to a constant assumption of drugs as a cofactor of eosinophils-mediated liver injury in chronic hepatitis $\mathrm{C}$.

Keywords: chronic hepatitis C, drugs, eosinophilic infiltrate, liver biopsy, liver fibrosis, liver steatosis.

\section{INTRODUCTION}

Chronic hepatitis $\mathrm{C}$ in developed countries is a common cause of chronic hepatic injury, liver transplantation and liver related death [1]. In HCV hepatic disease, the co-factors of liver damage are viral co-infections, liver steatosis, alcohol abuse and liver iron overload [2]. The presence of concomitant diseases and, consequently, of chronic drug assumption has not been investigated as a possible risk factor for severe liver damage in chronic hepatitis $\mathrm{C}$. In this context a tissue infiltrate of eosinophilic leucocytes has very rarely been described, and its significance is unknown. Conversely an infiltration of eosinophilic leucocytes has been described in various liver diseases, including primary biliary cirrhosis (PBC) [3-9], primary sclerosing cholangitis (PSC) [10-12],

Abbreviations: $\mathrm{HCV}$, hepatitis C virus; EI, eosinophilic infiltrate; PBC, primary biliary cirrhosi; PSC, primary sclerosing cholangitis.

Correspondence: Giuseppe Tarantino, MD, Cattedra ed Unità Operativa di Gastroenterologia, University of Palermo, Piazza delle Cliniche, 2.90127 Palermo, Italy. E-mail: giutar@alice.it

*These authors contributed equally to this work. idiopathic hypereosinophilic syndrome [13-16], hepatic allograft rejection [17-26], graft-vs-host disease [27] and drug-induced liver injuries [28-34].

Experimental models have reported that activated Kupffer cells play a key role in producing the cytotoxicity of eosinophils by releasing TNF- $\alpha[35,36]$ a process that in evidenced, specifically, by liver biopsy of patients with druginduced liver injuries [37,38].

Our study was designed to examine the prevalence of eosinophilic infiltrate (EI) in liver biopsies of patients with chronic hepatitis $\mathrm{C}$ and to investigate the relations between eosinophilic infiltration of liver tissue and clinical features, current and / or recent assumption of drugs, and histological features.

\section{METHODS}

\section{Patients}

We retrospectively analysed the clinical records of 335 consecutive patients with chronic hepatitis $\mathrm{C}$ admitted to 
our Liver Unit from January 2005 to December 2006 for liver biopsy. Inclusion criteria of the patients were: (i) HCV-RNA positive with histological diagnosis of chronic hepatitis with any degree of fibrosis; (ii) a detailed pharmacological anamnesis to define current and/or recent assumption of drugs; (iii) availability of adequate liver biopsy and serum stored upon admission to hospital for histological and biochemical evaluations. Patients were excluded if they had: (i) post-transplant recurrent hepatitis C; (ii) chronic co-infection with $\mathrm{HBV}$ and/or HIV; (iii) acute hepatitis; (iv) values of serum alanine aminotransferase (ALT) of more than 15 times the upper normal limit (UNL); (v) an incomplete or absent anamnesis for concomitant diseases and/or drug assumption.

The current study was performed in accordance with the principles of Good Clinical Practice, the principles of the Declaration of Helsinki and its appendices, and local and national laws. To maintain patient privacy, patients' names were replaced in the database with codes, dates of birth, and / or ages.

\section{Clinical and laboratory assessment}

Upon admission to hospital, the age and gender of patients, presence of other chronic diseases and a detailed pharmacologic anamnesis to define current and/or recent assumption of drugs were recorded. After an overnight fast, venous blood was drawn to evaluate the serum levels of ALT, $\gamma$-glutamyltransferase $(\gamma$-GT), alkaline phosphatase (AP), total cholesterol, triglycerides, plasma glucose concentration, platelet count and blood eosinophil count (normal values $<550$ cells $/ \mathrm{mm}^{3}$ ). Serum insulin was measured on stored serum by a two-site enzyme ELISA (Mercodia Insulin ELISA, Arnika). The detection limit was less than $1 \mu \mathrm{U} / \mathrm{mL}$. Insulin resistance (IR) was determined with the homeostasis model assessment (HOMA) method by using the following equation: Insulin resistance (HOMA$\mathrm{IR})=$ fasting insulin $(\mu \mathrm{U} / \mathrm{mL}) \times$ fasting glucose $(\mathrm{mmol} / \mathrm{L}) / 22.5$ [39]. HOMA-IR has been validated in comparison with euglycaemic/hyperinsulinaemic clamp technique in both diabetic and non-diabetic subjects [40]. The same day, serum was collected to perform HCV RNA qualitative PCR assay (Cobas Amplicor HCV Test version 2.0; limit of detection: $50 \mathrm{IU} / \mathrm{mL}$ ) and to determine $\mathrm{HCV}$ genotype by INNO-LiPA (HCV II, Bayer).

\section{Assessment of liver biopsy}

Percutaneous liver biopsies, performed with a 16-gauge needle, were formalin fixed and paraffin embedded. We used $4 \mu \mathrm{m}$ sections that were rewashed, rehydrated and stained with Hematoxylin-Eosin, Shikata's orcein, PAS diastase and Gomori stain for reticular fibres. Slides of liver specimens were coded and read by a single pathologist (D.C.), who was unaware of patients' identities and clinical features. Only biopsies containing more than eight portal tracts were read. Portal, peri-portal and lobular necroinflammatory activity (grading) and fibrosis (staging) were investigated by applying Scheuer's 1991 histological score [41]. Liver steatosis was assessed as the percentage of hepatocytes containing macrovescicular fat droplets. It was coded as absent if 0 to $4 \%$, or present if $\geq 5 \%$ of hepatocytes were affected. Portal and peri-portal eosinophilic leucocyte infiltrate was assessed in every portal tract of haematoxylin/eosin stained sections. We counted eosinophils in all portal tracts (at least eight) and reported in the data-base the three highest values of eosinophils count. The presence of 3 or more eosinophils in portal and periportal space was considered relevant. We also investigated, histological features more frequently reported to be related to drug induced hepatitis, i.e. canalicular cholestasis, peri-venular lipofuscinosis and small intra-lobular granulomas.

\section{Statistical methods}

Continuous variables were summarized as mean \pm SD and categorical variables as frequency and percentage. Significant differences between patients with or without drug assumption were calculated using a chi-square test for categorial variables and $t$ Student test for continuous variables. Multiple logistic regression models were used to assess the relationship of steatosis, fibrosis and eosinophilic infiltrate with demographics, history of drug assumption, and metabolic and histological features of the patients.

In the first model the dependent variable was steatosis coded as 0 or absent if $<5 \%$ of the hepatocytes were affected, and 1 or present if $\geq 5 \%$ of the hepatocytes were affected. As candidate risk factors for presence of histological steatosis we selected age, gender, history of drug assumption, ALT, $\gamma$ GT and AP levels, cholesterol, triglycerides, HOMA-score, EI $(<3$ vs at least three eosinophils observed), grading score $(\leq 1$ $v s>1$ according to Scheuer score) and fibrosis score (1 vs 2-4 of Scheuer score).

In the second model the dependent variable was fibrosis coded as 0 (stage 1 of fibrosis according to Scheuer score) or 1 (stage 2-4 according to Scheuer score). We considered as explanatory variables age, gender, history of drug assumption, platelet count, ALT, $\gamma$-GT, AP, cholesterol, triglycerides, HOMA-score, EI $(<3$ vs at least 3 eosinophils observed), grading score ( $\leq 1$ vs $>1$ according to Scheuer) and steatosis ( $<5 \%$ vs $\geq 5 \%$ of hepatocytes affected).

In the third model the dependent variable was EI coded as absent $(<3$ eosinophils) or present ( $\geq 3$ eosinophils). We selected as possible related variables age, gender, drug assumption, platelet count, eosinophil count, ALT, $\gamma$-GT levels, AP, cholesterol, triglycerides and HOMA-score. Variables found to be associated with the dependent variables on univariate logistic regression at a probability 
threshold of $<0.10$ were included in multivariate logistic regression models. Regression analysis was performed using PRO LOGISTIC subroutine in SAS (SAS Institute, Inc., Cary, NC, USA) [42].

\section{RESULTS}

\section{Patients' characteristics}

Among the 335 patients who underwent liver biopsy, 147 patients satisfied inclusion/exclusion criteria and were evaluated in our study. The clinical and histological features of those 147 patients were similar to the remaining 188 patients.

The characteristics of the 147 patients are shown in Table 1 . The mean age was $51 \pm 13$ years. HCV genotype 1 was predominant $(91 \%)$, and all other genotypes of $\mathrm{HCV}$ $[2,3,4]$ were present in the measure of $3 \%$ each. Thirty-eight percent of patients had concomitant diseases and constantly took medications: $14 \%$ of patients assumed antihypertensive drugs for blood hypertension; $6 \%$ of patients assumed L-tiroxina for hypothyroidism, $4 \%$ of patients assumed benzodiazepines for psychiatric disturbances, $4 \%$ of patients assumed inhibitor protonic pump for ulcer-like dyspepsia; $3 \%$ and another $3 \%$ of patients assumed oral hypoglycaemic drug and alpha blocker, respectively, for diabetes and prostatic hypertrophy, and another $4 \%$ assumed various drugs for various conditions.

Concerning the prevalence of allergic diseases in our series, two patients were affected by allergic rhinitis occasionally treated with anti-histaminic drugs, and another patient had a history of asthmatic bronchitis periodically treated with corticosteroid drugs.

Only two patients had a mild increase of blood eosinophil count with values of 620 and 660 cells $/ \mathrm{mm}^{3}$ respectively. These two patients assumed no drugs and their liver biopsies show no increase of eosinophils in the liver parenchyma.

\section{Histological findings}

Regarding the histological features, 40 patients $(27 \%)$ had mild inflammation, 84 (57\%) had moderate inflammation and $23(16 \%)$ severe inflammation. Overall, 107 patients (73\%) had a Scheuer's grading score of greater than one. A moderate/severe fibrosis (Scheuer's staging score $\geq 2$ ) was present in 99 patients $(67 \%)$. Histological steatosis was observed in 52 patients (35\%). Hepatic eosinophilic infiltrate ( $\geq 3$ cells evaluated in the portal/periportal spaces) was observed in 46 patients (31\%). A canalicular cholestasis was present in two patients though they neither took drugs nor showed eosinophilic infiltrate in portal tracts. Peri-venular lipofuscinosis was present in three patients and two of them were taking drug with EI in the liver parenchyma. Small intra-lobular epithelioid granulomas and epithelioid granuloma-like aggregates were
Table 1 Demographic, laboratory and histological features of 147 patients with chronic hepatitis C

\begin{tabular}{|c|c|}
\hline $\begin{array}{l}\text { Mean age (years), mean } \pm \text { sd } \\
\text { Gender, } n(\%)\end{array}$ & $51 \pm 13$ \\
\hline Male & $74(50.3)$ \\
\hline Female & $73(49.6)$ \\
\hline \multicolumn{2}{|l|}{ Genotypes HCV, $n(\%)$} \\
\hline 1 & $134(91)$ \\
\hline 2 & $4(3)$ \\
\hline 3 & $5(3)$ \\
\hline 4 & $4(3)$ \\
\hline $\begin{array}{l}\text { Patients with drug } \\
\text { assumption, } n(\%)\end{array}$ & $56(38)$ \\
\hline Antihypertensives & $21(14)$ \\
\hline L-tiroxin & $8(6)$ \\
\hline Benzodiazepin & $6(4)$ \\
\hline Inhibitor protonic pump & $6(4)$ \\
\hline Oral hypoglicaemic drug & $5(3)$ \\
\hline Alfa-blocker & $4(3)$ \\
\hline Other & $6(4)$ \\
\hline ALT (UNL) & $2.4 \pm 2.0$ \\
\hline Platelet count $\left(\times 10^{3} / \mathrm{mm}^{3}\right)$ & $206 \pm 58$ \\
\hline Eosinophils count (cells/mm ${ }^{3}$ ) & $184.9 \pm 143.7$ \\
\hline$\gamma-\mathrm{GT}(\mathrm{UNL})$ & $1.08 \pm 0.8$ \\
\hline Alkaline Phosphatase (UNL) & $0.7 \pm 0.2$ \\
\hline Cholesterol mg/dL (n.v. $\leq 220)$ & $177 \pm 35(43-294)$ \\
\hline Triglycerides mg/dL (n.v. $\leq 175)$ & $97 \pm 47(40-404)$ \\
\hline Blood glucose (mM/L) & $5.2 \pm 1.33(3.7-13.7)$ \\
\hline Insulin $(\mu \mathrm{U} / \mathrm{mL})$ & $12.6 \pm 7.2(2.0-42.0)$ \\
\hline HOMA-score & $3.1 \pm 2.3(0.4-17.0)$ \\
\hline \multicolumn{2}{|l|}{ Histology at biopsy (Scheuer score) } \\
\hline \multicolumn{2}{|l|}{ Grade of inflammation (code) } \\
\hline $1(0)$ & $40(27 \%)$ \\
\hline $2(1)$ & $84(57 \%)$ \\
\hline $3(1)$ & $23(16 \%)$ \\
\hline \multicolumn{2}{|l|}{ Stage of fibrosis (code) } \\
\hline $1(0)$ & $48(33 \%)$ \\
\hline $2(1)$ & $71(48 \%)$ \\
\hline $3(1)$ & $25(17 \%)$ \\
\hline $4(1)$ & $3(2 \%)$ \\
\hline \multicolumn{2}{|l|}{ Steatosis } \\
\hline Absent $(<5 \%)$ & $95(65 \%)$ \\
\hline Present $(\geq 5 \%)$ & $52(35 \%)$ \\
\hline \multicolumn{2}{|l|}{ Eosinophilic infiltrate } \\
\hline Absent $(<3$ cells $)$ & $101(69 \%)$ \\
\hline Present ( $\geq 3$ cells) & $46(31 \%)$ \\
\hline
\end{tabular}

Continuous variables: mean \pm SD (minimum-maximum). Categorial variables: absolute value (\%). Abbreviations: ALT, alanine aminotransferase; $\gamma$-GT, $\gamma$-glutamyltransferase; UNL, upper normal limit; n.v., normal values.

present in 31 patients $(21 \%$ of cases $)$, with no differences between drug taking and not in drug taking patients. 
Comparison between patients with and without chronic drug assumption

Table 2 shows the significant differences between patients with and without history of drug assumption. The drugtaking patients were 10 years older $(P<0.0001)$, had higher ALT $(P<0.009)$ and alkaline phosphatase $(P<0.003)$ levels, presented a more severe grading score $(P<0.02)$, and a more frequent presence of EI
$(P<0.0001)$, but not of an elevated blood eosinophil count, than non drug-taking subjects.

\section{Factors associated with histological hepatic steatosis}

We performed univariate and multivariate analyses to identify risk factors associated with the presence of histological steatosis. The results are reported in Table 3. At univariate analysis, drug assumption, ALT serum levels,

\begin{tabular}{|c|c|c|c|}
\hline Variables & $\begin{array}{l}\text { Patients without } \\
\text { drug assumption } \\
\text { (91) }\end{array}$ & $\begin{array}{l}\text { Patients with } \\
\text { drug assumption } \\
\text { (56) }\end{array}$ & $P$ \\
\hline Age (years) & $48 \pm 14(18-69)$ & $57 \pm 9(29-70)$ & $<0.0001$ \\
\hline Gender (M/F) & $46 / 45$ & $28 / 28$ & \\
\hline ALT (UNL) & $2.05 \pm 1.4$ & $2.9 \pm 2.5$ & 0.009 \\
\hline$\gamma$-GT (UNL) & $1.0 \pm 0.7$ & $1.22 \pm 0.89$ & 0.09 \\
\hline $\begin{array}{l}\text { Alkaline phosphatase } \\
\text { (UNL) }\end{array}$ & $0.63 \pm 0.21$ & $0.74 \pm 0.23$ & 0.003 \\
\hline $\begin{array}{l}\text { Platelet count } \\
\left(\times 10^{3} / \mathrm{mm}^{3}\right)\end{array}$ & $210.7 \pm 59.5$ & $199.4 \pm 54.7$ & 0.25 \\
\hline $\begin{array}{l}\text { Eosinophil count } \\
\left(\text { cells } / \mathrm{mm}^{3}\right)\end{array}$ & $188 \pm 152,2$ & $180 \pm 129.4$ & 0.7 \\
\hline HOMA-IR & $2.9 \pm 2.6$ & $3.3 \pm 1.9$ & 0.31 \\
\hline \multicolumn{4}{|l|}{ Histological features } \\
\hline Grading >1 & $60(66 \%)$ & $47(84 \%)$ & 0.02 \\
\hline Staging $\geq 2$ & $56(61.5 \%)$ & $42(75 \%)$ & 0.1 \\
\hline Steatosis & $28(31 \%)$ & $24(43 \%)$ & 0.18 \\
\hline Eosinophilic infiltrate & $16(17.6 \%)$ & $30(53.6 \%)$ & $<0.0001$ \\
\hline
\end{tabular}

Table 2 Demographic, laboratory and histological features of the 147 patients in according to drug assumption

Abbreviations: ALT, alanine aminotransferase; $\gamma$-GT, $\gamma$-glutamyltransferase; UNL, upper normal limit; n.v., normal values.

Table 3 Univariate and multivariate analysis of risk factors for liver steatosis in 147 patient with chronic hepatitis C

\begin{tabular}{|c|c|c|c|c|c|c|}
\hline \multirow{2}{*}{$\frac{\text { Variable }}{\text { Independent }}$} & \multicolumn{3}{|c|}{ Univariate analysis } & \multicolumn{3}{|c|}{ Multivariate analysis } \\
\hline & $P$ & $\mathrm{OR}$ & 95\% C.I. & $P$ & OR & 95\% C.I. \\
\hline Age (years) & 0.15 & 1.018 & $0.994-1.053$ & & & \\
\hline $\operatorname{Sex}(M / F)$ & 0.52 & 0.724 & $0.361-1.451$ & & & \\
\hline Drug assumption & 0.04 & 2.133 & $1.00-4.552$ & 0.63 & 0.811 & $0.346-1.903$ \\
\hline ALT-UNL & 0.03 & 1.005 & $1.000-1.050$ & 0.26 & 1.003 & $0.998-1.009$ \\
\hline$\gamma$-GT-UNL & 0.16 & 0.99 & $0.98-1.002$ & & & \\
\hline $\mathrm{AP}-\mathrm{UNL}$ & 0.50 & 1.005 & $0.99-1.018$ & & & \\
\hline Cholesterol (mg / dL) & 0.42 & 0.99 & $0.98-1.006$ & & & \\
\hline Triglycerides (mg / dL) & 0.23 & 0.99 & $0.98-1.003$ & & & \\
\hline HOMA score & 0.04 & 1.173 & $1.001-1.374$ & 0.046 & 1.181 & $1.003-1.391$ \\
\hline Eosinophilic Infiltrate & $<0.001$ & 4.83 & $2.242-11.418$ & $<0.0001$ & 5.86 & $2.464-13.962$ \\
\hline Grading & 0.11 & 0.59 & $0.35-1.015$ & & & \\
\hline Staging & 0.17 & 0.72 & $0.46-1.14$ & & & \\
\hline
\end{tabular}

Abbreviations: ALT, alanine aminotransferase, $\gamma$-GT, $\gamma$-glutamyltransferase; AP, alkaline phosphatase; UNL, upper normal limit. 
HOMA score and histological EI were significantly associated with liver steatosis $(P<0.10)$. Multivariate analysis showed that HOMA score (OR 1.18; 95\% CI 1.00-1.39) and EI (OR 5.86; 95\% CI 2.46-13.96) were independent and significant risk factors for histological steatosis.

Factors associated with moderate / severe stage of fibrosis

Older age, platelet count, AP levels, EI and more severe necroinflammation were significantly associated with moderate/severe fibrosis in univariate analysis $(P<0.10)$.
Multivariate analysis showed that grading (OR 6.82; 95\% CI 2.46-18.80) and EI (OR 4.00; 95\% CI 1.23-12.90) were independent and significant risk factors for moderate / severe fibrosis (Table 4).

Variables associated with hepatic eosinophilic infiltrate

We even investigated even possible correlations between demographics, history of drug assumption, biochemical variables, blood eosinophil count, and the EI. The results are reported in Table 5. Older age, drug assumption, high ALT

Table 4 Univariate and multivariate analysis of risk factors for moderate/severe stage of fibrosis in 147 patient with chronic hepatitis $\mathrm{C}$

\begin{tabular}{|c|c|c|c|c|c|c|}
\hline \multirow{2}{*}{$\begin{array}{l}\text { Variable } \\
\text { Indipendent }\end{array}$} & \multicolumn{3}{|c|}{ Univariate analysis } & \multicolumn{3}{|c|}{ Multivariate analysis } \\
\hline & $P$ & OR & $95 \% \mathrm{CI}$ & $P$ & OR & $95 \% \mathrm{CI}$ \\
\hline Age (years) & 0.08 & 1.035 & $0.998-1.074$ & 0.68 & 1.008 & $0.97-1.045$ \\
\hline Gender $(\mathrm{M} / \mathrm{F})$ & 0.42 & 0.581 & $0.298-1.557$ & & & \\
\hline Drug assumption & 0.877 & 0.938 & $0.383-2.292$ & & & \\
\hline Platelet count $\left(\times 10^{3} / \mathrm{mm}^{3}\right)$ & 0.07 & 0.99 & $0.98-1.001$ & 0.29 & 0.99 & $0.98-0.004$ \\
\hline ALT-UNL & 0.11 & 0.99 & $0.98-1.001$ & & & \\
\hline$\gamma-\mathrm{GT}-\mathrm{UNL}$ & 0.67 & 1.002 & $0.99-1.009$ & & & \\
\hline AP-UNL & 0.045 & 0.98 & $0.97-1.00$ & 0.46 & 1.007 & $0.980-1.025$ \\
\hline Cholesterol (mg / dL) & 0.96 & 1.00 & $0.98-1.01$ & & & \\
\hline Triglycerides (mg / dL) & 0.12 & 1.007 & $0.98-1.014$ & & & \\
\hline HOMA-score & 0.122 & 1.136 & $0.966-1.334$ & & & \\
\hline Eosinophilic infiltrate & 0.06 & 2.31 & $0.98-5.478$ & 0.02 & 4.00 & $1.23-12.9$ \\
\hline Grading & 0.0002 & 4.317 & $2.049-9.094$ & 0.0002 & 6.82 & $2.46-18.8$ \\
\hline Steatosis & 0.69 & 1.25 & $0.54-2.92$ & & & \\
\hline
\end{tabular}

Abbreviations: ALT, alanine aminotransferase; $\gamma$-GT, $\gamma$-glutamyltransferase; AP, alkaline phosphatase; UNL, upper normal limit.

Table 5 Univariate and multivariate analysis of risk factors for hepatic eosinophilic infiltrate in 147 patient with chronic hepatitis $\mathrm{C}$

\begin{tabular}{|c|c|c|c|c|c|c|}
\hline \multirow{2}{*}{$\frac{\text { Variable }}{\text { Independent }}$} & \multicolumn{3}{|c|}{ Univariate analysis } & \multicolumn{3}{|c|}{ Multivariate analysis } \\
\hline & $P$ & OR & $95 \% \mathrm{CI}$ & $P$ & OR & $95 \% \mathrm{CI}$ \\
\hline Age (years) & 0.001 & 1.057 & $1.022-1.094$ & 0.08 & 1.040 & $0.994-1.089$ \\
\hline Gender $(\mathrm{M} / \mathrm{F})$ & 0.76 & 0.899 & $0.447-1.806$ & & & \\
\hline Drug assumption & $<0.0001$ & 5.409 & $2.547-11.485$ & 0.002 & 4.022 & $1.622-9.969$ \\
\hline Platelet count $\left(\times 10^{3} / \mathrm{mm}^{3}\right)$ & 0.70 & 0.999 & $0.992-1.005$ & & & \\
\hline Eosinophil count $\left(\mathrm{c} / \mathrm{mm}^{3}\right)$ & 0.12 & 1.009 & $0.991-1.025$ & & & \\
\hline ALT-UNL & 0.007 & 1.008 & $1.002-1.013$ & 0.18 & 1.005 & $0.998-1.012$ \\
\hline$\gamma$-GT-UNL & 0.06 & 1.007 & $1.000-1.015$ & 0.595 & 1.003 & $0.993-1.013$ \\
\hline AP-UNL & 0.25 & 1.008 & $0.994-1.021$ & & & \\
\hline Cholesterol (mg / dL) & 0.819 & 1.001 & $0.991-1.011$ & & & \\
\hline Triglycerides (mg / dL) & 0.52 & 1.002 & $0.995-1.010$ & & & \\
\hline HOMA-score & 0.825 & 1.017 & $0.874-1.184$ & & & \\
\hline
\end{tabular}

Abbreviations: ALT, alanine aminotransferase; $\gamma$-GT, $\gamma$-glutamyltransferase; AP, alkaline phosphatase; UNL, upper normal limit. 
and $\gamma$-GT serum levels were significantly associated with the presence of eosinophils in the liver tissue. The multivariate analysis showed that only drug assumption (OR 4.02; 95\% CI 1.62-9.97) independently and significantly correlated with the EI.

\section{DISCUSSION}

Recently there has been increasing interest in the role of liver injury cofactors in the progression of chronic hepatitis $\mathrm{C}$, steatosis alcohol abuse and iron overload have been identified as cofactors of liver damage $[2,43]$. Conversely other variables, such as chronic drug assumption or concomitant chronic diseases have not been clearly estimated as risk factors for the progression of liver damage. In the same setting, the significance of hepatic eosinophilic infiltrate has not been investigated.

Many experimental studies have shown that activated eosinophils could play an important role in the pathogenesis of the abovementioned liver diseases (PBC, PSC, human hepatic allograft rejection, idiopathic hypereosinophilic syndrome, graft-vs-host-disease) through release of granules containing TNF- $\alpha$, highly cytotoxic proteins such as major basic protein and eosinophilic cationic protein [3-6,17$26,44,45]$.

Several reports have described a hepatic EI in patients with drug hepatotoxicity sustained by an immunoallergic mechanism, and induced by anticonvulsivants (phenytoin, carbamazepine) [30-32] and tenoxicam [33]. Recently, some authors have studied the significance of liver EI in patients with drug-induced liver injury [34]. The first experimental model to prove in vivo eosinophils-induced hepatotoxicity was established by Tsuda et al. in 2001. They used IL-5 transgenic mice with a consequent blood hypereosinophilia. These mice, after injection of lipopolysaccharide (LPS), developed an extensive hepatic lobular necrosis associated with a transmigration of eosinophils through vascular endothelium and degranulation of cytotoxic granules in inflamed areas. These eosinophilic injuries were transient, but liver specific. Pre-administration of gadolinium chloride $(\mathrm{GdCl} 3)$ and anti-TNF- $\alpha$ markedly reduced the hepatic inflammation, suggesting that LPS-activated Kupffer cells play a key role in producing the cytotoxicity of eosinophils by releasing TNF- $\alpha$ [35]. More recently another study by Takahashi et al. [36], found, with an immunohistochemical technique, an increased expression of Ecalectin / galectin-9 (ECL/ GL9), an eosinophilic chemoattractant isolated from $\mathrm{T}$ lymphocytes, specifically in liver biopsy of patients with drug-induced liver injuries $[37,38]$.

In consideration of this biological and clinical evidence and of eosinophils' potential capacity to induce liver injury, we investigated this histological finding in HCV chronic patients, in relation to other clinical and histological features.

In our study we showed that drug-taking patients who were significantly older than non drug-taking patients, and with higher ALT and alkaline phosphatase levels, presented more severe necro-inflammatory activity and more frequent EI in liver parenchyma than patients without drug assumption. Moreover we found that the presence of EI is strongly and independently associated with drug assumption. Therefore we could speculate that the drug assumption, more frequent in older patients, can induce hepatic EI.

In multivariate analysis, we found a clear correlation between steatosis and EI. Histological hepatic steatosis is a very frequent finding in chronic hepatitis $\mathrm{C}$ patients. It can be identified as viral steatosis in genotype 3 , and as metabolic steatosis typically of non-3 genotypes [46]. IR represents the pathogenetic key of metabolic steatosis $[43,47,48]$, and different viral and non-viral mechanisms have been suggested in its pathogenesis [49-51]. We could speculate that eosinophils are able to induce steatosis by interfering with insulin signaling via TNF- $\alpha[52,53]$.

Furthermore, in our study we found that liver fibrosis was associated with EI, as well as with necroinflammatory activity. The association between EI and liver fibrosis could be explained by the eosinophils' ability to release TNF- $\alpha$ and other cytokines capable of increasing an inflammatory cascade and therefore stimulating the fibrogenic activity of stellate cells [54].

We have found no significant differences in the eosinophil count in patients with or without EI and in patients with or without drug assumption. So, in our study, the number of eosinophils in liver samples was not correlated with the number of eosinophils in the blood at the time of biopsy. This is in keeping with the observation of Pham et al. [55], who stated that the recruitment of eosinophils in the liver tissue may depend on local mechanisms. Selective recruitment of eosinophils in the liver of patients with drug-induced liver disease may be related to the expression of specific chemoattractants.

This study presents the limits of a retrospective analysis, particularly in the recruitment of cases. In fact, patients with clearer anamnestic data were preferred, so a recall bias may have been generated. Moreover the cut-off of three eosinophils that we utilized to assign the presence of EI in liver biopsy is arbitrary, with no previous specific reports in the literature. We observed that number of eosinophils was greater in the larger portal tracts, but as we considered the feature 'eosinophilic infiltrate' a dichotomous variable (0 or 1 ), these differences should not affect the meaning of the study. Therefore we counted the eosinophils in all portal tracts (at least eight) and we reported the three highest values of eosinophil counts in our database.

Our evidence could be relevant for clinical management of patients with hepatitis $\mathrm{C}$ and chronic drug assumption. We have demonstrated the strong association between use of drugs for common chronic diseases and EI, so for this category of patients a histological assessment of liver disease may be more opportune. In the future, a collection of consecutive 
cases in a prospective study should be performed to confirm these findings.

In conclusion our study provides a prevalence estimate of EI in the liver histo-morphology of patients with chronic hepatitis $\mathrm{C}$ and documents its significant correlation with liver injury caused by steatosis and fibrosis.

\section{ACKNOWLEDGEMENT}

The authors would like to thank Warren Blumberg for his help in editing this paper.

\section{REFERENCES}

1 Sagnelli E, Stroffolini T, Mele A et al. The importance of HCV on the burden of chronic liver disease in Italy: a multicenter prevalence study of 9,997 cases. J Med Virol 2005; 75(4): 522-527.

2 Poynard T, Yuen MF, Ratziu V, Lai CL. Viral hepatitis C. Lancet 2003; 362: 2095-2100.

3 Terasaki S, Nakanuma Y, Yamazak M, Unoura M. Eosinophilic infiltration of the liver in primary biliary cirrhosis: a morphological study. Hepatology 1993; 17: 206-211.

4 Martinez OM, Villanueva JC, Gershwin ME, Krams SM. Cytokine patterns and cytotoxic mediators in primary biliary cirrhosis. Hepatology 1995; 21: 113-119.

5 Yamazaki K, Nakadate I, Suzuki K, Sato S, Masuda T. Eosinophilia in primary biliary cirrhosis. Am J Gastroenterol 1996; 91: 516-522.

6 Miyaguchi S, Oda M, Tamano M et al. Elevation of serum eosinophil cationic protein in primary biliary cirrhosis. Int Hepatol Commun 1994; 2: 285-288.

7 Nakamura A, Yamazaki K, Suzuki K, Sato S. Increased portal tract infiltration of mast cells and eosinophils in primary biliary cirrhosis. Am J Gastroenterol 1997; 92: 22452249.

8 Kokubun M, Kuroda M, Takagi T et al. Eosinophilia in primary biliary cirrhosis (in Japanese). Nippon Shokakibyo Gakkai Zasshi (Jpn J Gastroenterol) 1990; 87: 1410-1416.

9 Wirth HP, Heer P, Bertschinger P, Meyenberger C, Ammann R, Altorfer J. Transient eosinophilia in primary biliary cirrhosis (in German). Schweiz Med Wochenschr 1993; 123: 2278-2283.

10 Hartleb M, Kajor M, Kaczor R, Nowak A. Hepatic eosinophilic infiltration in primary sclerosing cholangitis (letter to the editor). J Gastroenterol 1998; 33: 134-135.

11 Scheurlen M, Mork H, Weber P. Hypereosinophilic syndrome resembling chronic inflammatory bowel disease with primary sclerosing cholangitis. J Clin Gastroenterol 1992; 14: 59-63.

12 Kagawa T, Suematsu M, Miura S, Komatsu H, Oda M, Tsuchiya M. A case of primary sclerosing cholangitis with eosinophilia (in Japanese). Sogorinsho 1988; 9: 2339-2342.

13 Dillon JF, Finlayson NDC. Idiopathic hypereosinophilic sindrome presenting as intrahepatic cholestatic jaundice. Am J Gastroenterol 1994; 89: 1254-1255.
14 Foong A, Scholes JV, Gleich GJ, Kephart GM, Holt PR. Eosinophil induced chronic active hepatitis in the idiopathic hypereosinophilic syndrome. Hepatology 1991; 13: 10901094.

15 Croffy B, Kopelman R, Kaplan M. Hypereosinophilic syndrome. Association with chronic active hepatitis. Dig Dis Sci 1988; 33: 233-239.

16 Ho KKL, Ho ASS, Leung RCC, Lai CKW, Lai KN. The interleukin-5 messenger RNA expression in a patient with idiopathic hypereosinophilic syndrome. Clin Exp Allergy 1998; 28: 889-892.

17 Martinez OM, Ascher NL, Ferrell L et al. Evidence for a nonclassical pathway of graft rejection involving interleukin 5 and eosinophils. Transplantation 1993; 55: 909-918.

18 Foster PF, Bhattacharyya A, Sankary HN, Coleman J, Ashmann M, Williams JW. Eosinophil cationic protein's role in human hepatic allograft rejection. Hepatology 1991; 13: 1117-1125.

19 Hughes VF, Trull AK, Joshi O, Alexander JM. Monitoring eosinophil activation and liver function after liver transplantation. Transplantation 1998; 65: 1334-1339.

20 Groen PC, Kephart GM, Gleich GJ, Ludwig J. The eosinophil as an effector cell of the immune response during hepatic allograft rejection. Hepatology 1994; 20: 654-662.

21 Ben-Ari Z, Dhillon AP, Moqbel R et al. Monoclonal antibodies against eosinophils in liver allograft rejection. Liver Transpl Surg 1996; 2: 46-51.

22 Lang T, Krams SM, Berquist W, Cox KL, Esquivel CO, Martinez OM. Elevated biliary interleukin 5 as an indicator of liver allograft rejection. Transpl Immunol 1995; 3: 291298.

23 Nagrai A, Ben-Ari Z, Dhillon AP, Burroughs AK. Eosinophils in acute cellular rejection in liver allografts. Liver Transpl Surg 1998; 4: 355-362.

24 Dollinger MM, Plevris JN, Bouchier IA, Harrison DJ, Hayes PC. Peripheral eosinophil count both before and after liver transplantation predicts acute cellular rejection. Liver Transpl Surg 1997; 3: 112-117.

25 Ben-Ari Z, Booth JD, Gupta SD, Rolles K, Dhillon AP, Burroughs AK. Morphometric image analysis and eosinophil counts in human liver allografts. Transpl Int 1995; 8: 346-352.

26 Foster PF, Sankary HN, Williams JW, Bhattacharyya A, Coleman J, Ashmann M. Morphometric inflammatory cell analysis of human liver allograft biopsies. Transplantation 1991; 51: 873-876.

27 Nonomura A, Kono N, Mizukami Y, Nakamura Y. Histological changes of the liver in experimental graft-versus-host disease across minor histocompatibility barriers. VIII. Role of eosinophil infiltration. Liver 1996; 16: 42-47.

28 Scheuer PJ, Lefkowitch JH. Drugs and Toxins: Liver Biopsy Interpretation, 5th edn. London: W.B. Saunders, 1994: 102-116.

29 McMaster KR, Hennigar GR. Drug-induced granulomatous hepatitis. Lab Invest 1981; 44: 61-73.

30 Mullick FG, Ishak KG. Hepatic injury associated with diphenylhydantoin therapy. A clinicopathologic study of 20 cases. Am J Clin Pathos 1980; 74: 442-452. 
31 Navarro VJ, Senior JR. Drug related Hepatotoxicity. N Engl J Med 2006; 354: 731-739.

32 Allam JP, Paus T, Reichel C, Bieber T, Novak N. Dress syndrome associated with carbamazepine and phenytoin. Eur J Dermatol 2004; 14: 339-342.

33 Trak-Smayra V, Cazals-Hatem D, Asselah T, Duchatelle V, Degott C. Prolonged cholestasis and ductopenia associated with tenoxicam. J Hepatol 2003; 39: 125-128.

34 Bjornsson E, Kalaitzakis E, Olsson R. The impact of eosinophilia and hepatic necrosis on prognosis in patients with drug-induced liver injury. Aliment Pharmacol Therap 2007; 25: 1411-1421.

35 Tsuda K, Maeda T, Tominaga A et al. Eosinophil-induced liver injury: an experimental model using a IL-5 transgenic mice. J Hepatol 2001; 34: 270-277.

36 Takahashi Y, Fukusato T, Kobayashi Y et al. High expression of eosinophil chemoattranctant ecalectin / galectin-9 in drug-induced liver injury. Liver Int 2006; 26: 106-115.

37 Hirashima $\mathrm{M}$ et al. Ecalectin as a T cell-derived eosinophil chemoattractant. Int Arch Allergy Immunol 1999; 120(Suppl. 1): 7-10.

38 Matsumoto R, Hirashima M, Kita H, Gleich GJ. Biological activities of ecalectin: a novel eosinophil-activating factor. J Immunol 2002; 168: 1961-1967.

39 Matthews DR, Hosker JP, Rudenski AS, Turner RC, Naylor BA, Treacher DF. Homeostasis model assessment: insulin resistance and beta-cell function from fasting plasma glucose and insulin concentrations in man. Diabetologia 1985; 28: 412-419.

40 Ikeda Y, Suehiro T, Nakamura T, Kumon Y, Hashimoto K. Clinical significance of the insulin resistance index as assessed by homeostasis model assessment. Endocr J 2001; 48: 81-86.

41 Scheuer PJ, Lefkowitch JH. Liver Biopsy Interpretation. London: W.B. Saunders, 2000; 294.

42 SAS Technical Report. SAS/STASSsoftware: Changes \& Enhancement, release 6.07. Cary, NC: SAS Institute Inc., 1992.

43 Camma' C, Bruno S, Di Marco V et al. Insulin resistance is associated with steatosis in nondiabetic patients with genotype 1 chronic hepatitis C. Hepatology 2006; 43: 6471.

44 Gleish GJ, Flavaham NA, Fujiwara T, Vanhoutten PM. The eosinophil as a mediator of damage to respiratory epithelium: a model for bronchial hyperactivity. J Allergy Clin Immunol 1998; 81: 776-781.
45 Yamazaki K, Suzuki K, Nakamura A et al. Ursodeoxycholic acid inhibits eosinophil degranulation in patients with primary biliary cirrhosis. Hepatology 1999; 30: 71-78.

46 Bugianesi E, Marchesini G, Gentilcore E et al. Fibrosis in genotype 3 chronic hepatitis $\mathrm{C}$ and nonalcoholic fatty liver disease: role of insulin resistance and hepatic steatosis. Hepatology 2006; 44(6): 1648-1655.

47 Lo Iacono O, Venezia G, Petta S et al. The impact of insulin resistance, serum adipocytokines and visceral obesity on steatosis and fibrosis in patients with chronic hepatitis C. Aliment Pharmacol Ther 2007; 25: 1181-1191.

48 Fartoux L, Poujol-Robert A, Guechot J, Wendum D, Poupon $\mathrm{R}$, Serfaty L. Insulin resistance is a cause of steatosis and fibrosis progression in chronic hepatitis C. Gut 2005; 54: 1003-1008.

49 Shintani Y, Fujie H, Miyoshi $\mathrm{H}$ et al. Hepatitis $\mathrm{C}$ virus infection and diabetes: direct involvement of the virus in the development of insulin resistance. Gastroenterology 2004; 126: 840-848.

50 Miyoshi H, Fujie H, Shintani Y et al. Hepatitis C virus core protein exerts an inhibitory effect on suppressor of cytokine signaling (SOCS)-1 gene expression. J Hepatol 2005; 43: 757-763.

51 Kawaguchi T, Yoshida T, Harada M et al. Hepatitis C virus down-regulates insulin receptor substrates 1 and 2 through up-regulation of suppressor of cytokine signaling 3. Am J Pathol 2004; 165: 1499-1508.

52 Schmauder-Chock EA, Chock SP, Patchen ML. Ultrastructural localization of tumour necrosis factor-alpha. Histochem J 1994; 26(2): 142-151.

53 Beil WJ, Weller PF, Tzizik DM, Galli SJ, Dvorak AM. Ultrastructural immunogold localization of tumor necrosis factor-alpha to the matrix compartment of eosinophil secondary granules in patients with idiopathic hypereosinophilic syndrome. J Histochem Cytochem 1993; 41(11): 1611-1615.

54 Fehrenbach H, Weiskirchen R, Kasper M, Gressner AM. Up-regulated expression of the receptor for advanced glycation and products in cultured rat hepatic stellate cells during transdifferentiation to myofibroblasts. Hepatology 2001; 34: 943-952.

55 Pham BN, Bemuau J, Durand F et al. Eotaxin expression and eosinophil infiltrate in the liver of patients with drug-induced liver disease. J Hepatol 2001; 34: 537-547. 